\title{
Um olhar para as relações teóricas do conteúdo de ensino de eletromagnetismo fundamentado na teoria do ensino desenvolvimental ${ }^{+*}$
}

\author{
Daniel Trugillo Martins Fontes ${ }^{1}$ \\ Doutorando do Programa de Pós-Graduação Interunidades \\ em Ensino de Ciências - Universidade de São Paulo \\ André Machado Rodrigues ${ }^{1}$ \\ Universidade de São Paulo \\ São Paulo - SP
}

\section{Resumo}

O presente artigo tem por objetivo investigar quais relações teóricas poderiam formar um modelo para o ensino de eletromagnetismo a partir da teoria do ensino desenvolvimental de Davydov. Neste sentido, esse artigo se direciona para uma análise teórica sobre o conteúdo de ensino de eletromagnetismo abordando questões da sua fundamentação. Como resultado, apresentamos uma primeira síntese dos conceitos essenciais que estruturam os fenômenos eletromagnéticos clássicos, a saber: movimento, variação e interação. Também propusemos um percurso analítico desses conceitos concretizando-os na geração, transmissão e utilização da energia elétrica. Destacamos como principais conclusões desse trabalho a possibilidade de diálogo entre a teoria de Davydov e o ensino de Física a fim de promover o pensamento teórico e a delineação de um modelo teórico nesta concepção.

Palavras-chave: Ensino de Física; Eletromagnetismo; Teoria do Ensino Desenvolvimental; Davydov.

\footnotetext{
${ }^{+}$A look at the theoretical relations of the teaching content of electromagnetism based on the developmental teaching theory

* Recebido: 9 de julho de 2020.

Aceito: 2 de julho de 2021.

${ }^{1}$ E-mails: daniel.truga@gmail.com; rodrigues.am@usp.br
} 


\begin{abstract}
This article aims to investigate which theoretical relations could form a model for teaching electromagnetism based on Davydov's theory of developmental teaching. In this sense, this article fits into a theoretical analysis on the content of teaching electromagnetism by addressing issues of its foundation, and not of its methods. As a result, we present a first synthesis of the essential concepts that structure the classic electromagnetic phenomena, namely: movement, variation and interaction. We also propose an activity to analyze these concepts, concretizing them in the generation, transmission and use of electric energy. We highlight as this work's main conclusions the possibility of dialogue between Davydov's theory and the teaching of Physics in order to promote theoretical thinking and the outline of a theoretical model.
\end{abstract}

Keywords: Physics Teaching; Electromagnetism; Developmental Teaching; Davydov.

\title{
I. Introdução
}

Neste artigo apresentamos um estudo que visa, a partir de uma perspectiva históricocultural, particularmente centrada nos aportes teóricos da teoria do ensino desenvolvimental, analisar o conteúdo e apresentar um modelo teórico para o ensino de eletromagnetismo clássico $^{2}$ fruto de trabalho de dissertação de mestrado de Fontes (2020). Para isso, dividimos esse artigo em duas partes principais: até o item IV, apresentamos dados da literatura em relação ao ensino de eletromagnetismo e da teoria do ensino desenvolvimental de Davydov. A partir disto, justificamos a necessidade da elaboração de um modelo teórico para o Ensino de Ciências no geral, e para o eletromagnetismo em particular. Do item $\mathrm{V}$ em diante, apresentamos um diálogo com a teoria desenvolvimental e discutimos uma primeira proposição de um modelo teórico (DAVYDOV, 1990; HEDEGAARD; CHAIKLIN, 2005) a partir do trabalho da energia elétrica. Uma revisão da literatura (FONTES, 2020) mostra que não há propostas de análise de conteúdos do eletromagnetismo sob a ótica da teoria do ensino desenvolvimental, e considerando qualquer conteúdo da física, há apenas dois trabalhos nacionais (MARENGÃO, 2011; BORGES, 2016) ambos direcionados à mecânica clássica. Fontes e Rodrigues (2020, p. 4) sugerem uma justificativa para explicar a falta de trabalhos em ensino de Física que utilizem do referencial teórico davydoviano: "os principais

\footnotetext{
${ }^{2}$ Tal como Bezerra (2006), utilizamos o termo clássico para nos referirmos ao eletromagnetismo não-quântico. Também, vemos que é comum em livros didáticos a divisão do conteúdo do eletromagnetismo em diferentes frentes tais como eletrostática, eletrodinâmica, magnetostática, eletromagnetismo e radiação. Neste artigo utilizamos o termo eletromagnetismo de forma ampla, a fim de englobar todas essas separações didáticas. Casos específicos serão explicitados apropriadamente.
} 
pesquisadores que se dedicam ao estudo da teoria de Davydov não possuem formação acadêmica - graduação ou pós-graduação - na área da Física ou ensino de Física”.

Pesquisas sobre o ensino de eletromagnetismo têm relatado que estudantes apresentam grande dificuldade no estudo de sistemas elétricos e magnéticos (SILVA, 2012). Segundo Casperson e Linn (2006) os estudantes apresentam dificuldade em temas como eletrostática, pois em geral eles apresentam ideias e experiências desconectadas das esferas macroscópica e microscópica relacionadas ao mesmo fenômeno, enquanto físicos tendem a integrar ambas perspectivas para a compreensão do fenômeno investigado. Além da eletrostática, Colin e Viennot (2001) mostram que o entendimento conceitual do comportamento ondulatório da luz é de difícil assimilação, mesmo entre estudantes universitários.

Stocklmayer (2010) aponta que estudantes de vários graus de instrução acadêmica carecem de entendimento profundo a respeito do modelo físico de corrente elétrica e movimento de elétrons. Ainda neste tema, Scarinci et al. (2009), em uma experiência didática de demonstração da condução e geração da corrente elétrica, percebem que os estudantes apresentaram bastante dificuldade na interpretação do que ocorre no interior do fio, da pilha e da lâmpada. Sağlam e Millar (2006, p. 545) ao investigarem o entendimento do eletromagnetismo por estudantes dos anos finais do ensino médio, apontaram que poucos estudantes "parecem possuir uma perspectiva integrada ou podem demonstrar seu entendimento através da aplicação dos conceitos em novas situações".

Em relação ao ensino de física, há extensa literatura a respeito do desenvolvimento e uso de metodologias para o ensino de determinados conteúdos ou conceitos. Diversas revisões da literatura como Fávero e Sousa (2001); Ribeiro e Verdeaux (2012); Jardim e Guerra (2017b); Müller et al., (2017), Oliveira, Araujo e Veit (2017) exploram como diferentes metodologias estão presentes em diferentes conteúdos do ensino de física. Também, Henderson, Dancy e Niewiadomska-Bugaj (2012) elaboraram uma lista com 24 diferentes estratégias metodológicas encontradas na pesquisa em ensino de física. Em uma revisão da literatura a respeito do ensino de eletromagnetismo em todos os níveis de ensino nas últimas duas décadas, Fontes e Rodrigues (2021) apontaram que as soluções adotadas pelos professores se concentram, em sua grande maioria, no uso da experimentação ou na adoção de recursos tecnológicos como simuladores virtuais.

Contudo, na nossa perspectiva, talvez o problema do ensino de eletromagnetismo seja ainda mais complexo e falte uma reflexão que possa direcionar o questionamento sobre quais relações teóricas (CHAIKLIN, 1999) poderiam compor o núcleo do ensino, tendo em vista o desenvolvimento intelectual do estudante. Fontes e Rodrigues (2021) analisaram 46 artigos sobre o ensino de eletromagnetismo e notaram que $70 \%$ desse total é orientado por um referencial teórico. No entanto, dos 14 diferentes referenciais adotados, nenhum é utilizado como fundamento de análise para o conteúdo do ensino. 
O ensino desenvolvimental, como proposto por Davydov (1988a, 1998), permite que repensemos o conteúdo e aspectos estruturais do ensino de eletromagnetismo - e do ensino de física - a partir do ensino que visa ao desenvolvimento intelectual. Noutras palavras: o eletromagnetismo clássico apresenta um conjunto sólido de conteúdos já sistematizados (leis, definições, conceitos); o ensino desenvolvimental sugere que necessitamos analisar a estrutura teórica por trás desses conteúdos. Um produto dessa análise é a elaboração de um modelo teórico - também chamado de "modelo genético" (LAGO; ORTEGA; MATTOS, 2020, p. 130) - que identifica as relações essenciais, centrais, nucleares permitindo que o modelo seja utilizado como uma ferramenta para o estudo teórico, em oposição a um estudo empírico, das relações que constituem a aparência do objeto (HEDEGAARD; CHAIKLIN, 2005).

\section{Especificando o problema de pesquisa a partir da eletromagneticidade}

Para aprofundarmos a compreensão sobre o desenvolvimento do pensamento teórico no ensino de eletromagnetismo, suponha a seguinte situação para contextualização do problema: imaginemos um diálogo entre dois jovens, João e Maria, que gostam de pássaros. Em um momento de descontração no parque, Maria se questiona sobre o que faz os pássaros serem pássaros. De partida, ela assume que sempre há coisas - o que chamamos de relações teóricas $^{3}$ - que estão presentes em todos os fenômenos, e isso não seria diferente para os pássaros. João oferece uma sugestão: vamos observar todos os pássaros e então poderemos dizer o que faz os pássaros serem pássaros, chegaremos a uma passaridade.

Maria entende o ponto de João e juntos eles começam a anotar tudo que conseguem observar nos pássaros: penas, asas, bicos, cores, etc. Durante esse processo, eles encontram embaixo de uma árvore alguns trechos do Dialectical Logic: Essays on its history and theory, escrita por Ilyenkov (1977, p. 115, tradução nossa):

O universal pode ser externamente expressado muito melhor na forma de diferenças, mesmo opostas, que fazem os fenômenos separados se complementarem, componentes de um todo, de algo real, um agregado orgânico, e não como uma amorfa pluralidade de unidades postas juntas na base de mais ou menos atributos [...] por outro lado, o universal, que se manifesta precisamente nas particularidades, nas características individuais dos componentes do todo sem exceção, também existe juntamente a outros individuais derivados dele [...] $O$ geneticamente entendido universal não simplesmente existe, naturalmente, no plano abstrato, nos elementos das palavras e ideias, e sua existência de maneira alguma desdenha a realidade de suas modificações nas características singulares que dele derivam e que dele dependem.

\footnotetext{
${ }^{3} \mathrm{Na}$ literatura davydoviana há diferentes nomes para expressar essa ideia: relações teóricas, básicas, essenciais, centrais, nucleares, universalidade, entre outros exemplos (FONTES, 2020, p.14-18).
} 
Vendo a expressão confusa de João, Maria coloca em suas palavras: há uma crítica nesse trecho sobre o que estávamos fazendo. Mesmo reconhecendo que a universalidade - as relações teóricas, no caso a passaridade - se manifestará em cada um dos pássaros que vemos, não é através da análise do desmembramento de características que selecionamos como penas, asas e bicos que vamos chegar a uma passaridade. A passaridade existe como forma do particular e do individual, como uma relação entre a forma reduzida penas com a universalidade passaridade. João, ainda intrigado, questiona: e que condições e conexões são essas? Maria responde: não sei, o texto não expressa isso. Parece que teremos que descobrir por nós mesmos no processo de investigação.

Analogamente, estamos interessados em uma eletromagneticidade. Enfatizamos que eletromagneticidade não é um novo termo ou conceito que abandonaria as definições, leis e conceitos que temos no eletromagnetismo, mas sim uma delimitação do que poderiam ser as relações teóricas deste conteúdo. Noutras palavras, estamos interessados nas relações conceituais que permitam expressar os conteúdos teóricos do eletromagnetismo.

\section{O ensino desenvolvimental e as contribuições de Davydov}

Nossa delimitação da eletromagneticidade é fundamentada no referencial teórico do ensino desenvolvimental, desdobramento da psicologia histórico-cultural. Tal aporte teórico inicia-se com as contribuições de Vigotski (2007) para o entendimento do desenvolvimento humano a partir de princípios dialético-materialistas (LIBÂNEO; FREITAS, 2006). Prestes, Tunes e Nascimento (2017, p. 68) resumem em poucas palavras que o desafio de Vigotski e colaboradores era de "criar uma nova abordagem dos processos psicológicos estritamente humanos e pôr a psicologia em bases materialistas". Posteriormente, ao longo das décadas, muitos outros psicólogos e pedagogos se uniram ao grupo de trabalho formado nos anos de 1920.

A partir dessa base teórica, da teoria histórico-cultural, Davydov e colaboradores estruturam a teoria do ensino desenvolvimental. Essa corrente teórica não se configura como uma ruptura das tradições vigotskianas uma vez que compartilha de seus pressupostos. Em particular, a compreensão de que há diferentes tipos de conceitos, cada qual possuindo diferentes características e particularidades.

Vigotski (2007) diferencia os conceitos que são produzidos nas condições do ensino escolar (científicos), e propiciam a formação dos processos de generalizações e abstrações teóricas; e os conceitos cotidianos ou empíricos que são formados com base nas ações concretas da criança em seu cotidiano. Além disso, Vigotski (2007) defende que o desenvolvimento de funções psíquicas superiores é fruto de um fenômeno ativo de interiorização e apropriação do mundo exterior, mediado pela linguagem e pela cultura através de um processo dialético. Isto é, o conhecimento ocorre primeiramente no mundo social, recheado e inundado de signos para então se transformar em conhecimento individual da criança. Rosa, Moraes e Cedro (2016, p. 174) pontuam que Davydov ainda adicionaria um 
pressuposto: “os estudantes, ao compreenderem os princípios gerais de um conhecimento, saberão lidar com as variações particulares, com poucas intervenções do outro".

Libâneo e Freitas (2017, p. 336) destacam ainda que o aprendizado para acarretar desenvolvimento mental precisa ser organizado e sistematizado corretamente, sendo que a base "do desenvolvimento intelectual das crianças é o conteúdo dos conhecimentos assimilados". Chaiklin (2002) argumenta que a análise e o trabalho do conteúdo são précondições na concepção do ensino desenvolvimental. Adotamos da posição apresentada por Dias e Souza (2017, p. 185-186) sobre o potencial da apropriação dos conteúdos:

Quando se apropria de tais conteúdos [teoricamente estruturados], o indivíduo apropria-se também de um modo de organização do pensamento universal presente nas estruturas de niveis superiores de pensamento. Tais apropriações não são adquiridas empiricamente, por meio das ações cotidianas ligadas aos nivveis de pensamento empírico, pois estão vinculadas ao pensamento teórico e dependem de processos de ensino institucionalmente organizados em que se reproduzam os significados historicamente produzidos.

Neste contexto, Libâneo e Freitas (2017, p. 361) explicitam a proposta didática de Davydov partindo de três premissas básicas da teoria vigotskiana:

A primeira consiste em que as funções psíquicas superiores estão enraizadas nas
formas histórico-sociais da existência humana, ou seja, nos instrumentos culturais
já desenvolvidos pela humanidade, acumulados social e historicamente. A segunda
é de que a constituição do indivíduo como ser humano requer que ele se aproprie
desses instrumentos culturais, internalizando-os, ou seja, fazendo com que se
tornem meios de sua própria atividade. A terceira é de que essa apropriação
implica uma complexa atividade da consciência humana que é a generalização e a
formação de conceitos, de modo a ultrapassar os limites da experiência sensorial
imediata.

O modelo promovido por Vigotski (2007) faz referência à instrução e ao aprendizado como fontes do desenvolvimento psíquico no qual a instrução deveria preparar e motivar a criança para uma participação ativa e criadora nas práticas sociais existentes. A partir disso, ocorreria o desenvolvimento de funções psíquicas como o raciocínio lógico, atenção, memória, generalização, e abstração, que ainda não estivessem totalmente amadurecidas.

Diante do exposto, Davydov e colaboradores desenvolvem uma concepção própria de organização do ensino escolar com o foco na apropriação dos conceitos teóricos e na habilidade intelectual de trabalhar com o objeto de maneira crítica e autônoma, almejando a capacidade de generalização teórica. Em outras palavras, Davýdov (1982) entende que o conhecimento teórico deve ser a essência da atividade de ensino, pois é através da sua apropriação que se formará o pensamento teórico na criança, acarretando seu desenvolvimento psíquico. 
Davydov $(1982,1990)$ reconhecia ao menos dois tipos de conhecimentos sociais: empírico e teórico, que são conectados e possuem especificidades distintas para o desenvolvimento da ciência (HEDEGAARD, 1996). Uma preocupação de Davydov e Elkonin - seu principal colaborador - era fazer com que as crianças obtivessem controle sobre o conteúdo que aprendem na sala de aula, em outras palavras, que as crianças fossem capazes de lidar com o conteúdo de maneira autônoma (HEDEGAARD; CHAIKLIN, 2005). A importância do trabalho com o conteúdo para o planejamento do ensino é um ponto fundamental na teoria do ensino desenvolvimental (CHAIKLIN, 1999). Assim, percebemos o objetivo de organizar e sistematizar o ensino de tal modo que favoreça a aprendizagem de conceitos teóricos, com potencial para o desenvolvimento do pensamento teórico. Libâneo e Freitas (2017, p. 332) descrevem em caráter de síntese que a teoria de Davydov:

\begin{abstract}
oferece uma base teórico-metodológica que reúne princípios psicológicos em função de objetivos pedagógicos e didáticos de formação do pensamento teóricocientífico dos alunos. Ele defendeu que o ensino mais compativel com o mundo contemporâneo, da ciência, da tecnologia, dos meios de comunicação, da cultura, aquele compromissado com a transformação pessoal e social do aluno, que o ajude a desenvolver a análise dos objetos de estudo por uma forma de pensamento abstrata, generalizada, dialética [...] os conceitos básicos de sua teoria: a atividade humana e a de ensino-aprendizagem, a generalização e a formação do conceito, o ensino desenvolvimental e a atividade de estudo.
\end{abstract}

\title{
IV. Das características do pensamento e conhecimento teórico
}

A relação entre conhecimento e pensamento utilizada por Davydov (1990) deriva das posições de Vigotski (2007) e do filósofo marxista soviético Ilyenkov (2007). Desse modo, Davydov assume uma indissociabilidade entre pensamento teórico e conhecimento teórico, ao contrário de interpretações que distinguem pensamento e conhecimento (HEDEGAARD; CHAIKLIN, 2005). Segundo Ilyenkov (2007) pensar é a habilidade de trabalhar com o objeto de maneira inteligente, isto é, em concordância com a sua natureza e não a partir de devaneios fantasiosos do indivíduo. A suposição de Ilyenkov que pensamento e conhecimento são faculdades psicológicas tão estreitamente ligadas que a análise não pode separá-las sem mutilá-las é de vital importância para o desenvolvimento do pensamento teórico. Ilyenkov (2007, p. 76, tradução nossa) pontua que todo pensamento é em relação a um objeto:

E quando as pessoas dizem (e elas dizem frequentemente) que alguém possui o conhecimento mas é incapaz de "aplicá-lo" à realidade, elas estão fazendo uma absurda constatação, metade dela completamente cancela a sua outra metade. Como alguém pode conhecer um objeto - e ser incapaz de relacionar esse conhecimento (conhecimento do objeto!) com o objeto?! Essa situação paradoxal surge pois a pessoa não realmente sabe o objeto, mas sabe alguma coisa diferente. O quê? Frases sobre o objeto. Palavras, termos, fórmulas, signos, símbolos. 
Para Ilyenkov (2007) a essência da concepção do pensamento se mostra na sua manipulação de maneira autônoma, crítica e criativa, pelo indivíduo sobre o conteúdo. Em outras palavras, o sujeito deve ser capaz de criar e gerar suas próprias ações em relação aos mais diversos objetos.

Ilyenkov (2007) delimita o problema sobre o pensar de modo independente de tal maneira que podemos nos perguntar: o que a criança deve ter que a permite lidar autonomamente com um objeto? Davydov (1990) se debruça sobre essa questão na qual explicita o papel das generalizações empíricas e teóricas. No ensino desenvolvimental, entende-se que a generalização empírica não proporciona habilidades suficientes para lidar autonomamente com o objeto. Nesse processo de generalização, o estudante seleciona diferentes características que são captadas por meio dos sentidos sensoriais, separando as qualidades repetidas ou atributos comuns de um mesmo objeto. Por exemplo, ao observar aves, a criança selecionaria as características como: presença de penas, bicos, olhos, entre outros, e tal processo reflete uma generalização empírica. Falta aos estudantes o domínio das relações teóricas que permitem a existência do objeto para que eles sejam capazes de trabalhar o vaivém abstrato-concreto. Despendem-se esforços de professores e estudantes desenvolvendo um conhecimento empírico com pouco valor para o desenvolvimento intelectual da criança.

Enquanto o conhecimento empírico utiliza-se de categorias para representação da realidade observada (HEDEGAARD; CHAIKLIN, 2005) o conhecimento teórico reflete a relação entre o universal-abstrato e o empírico-aparente - entre a passaridade e as penas, entre a eletromagneticidade e a comida aquecida - tomando consciência de suas transformações e propriedades (DAVYDOV, 1988a; PANOSSIAN; MORETTI; SOUZA, 2017). A proposta davydoviana sugere que em vez de investigarmos o mundo diretamente, poderíamos pensar sobre um modelo de relações como explicações dos fenômenos, isto é, a crença que o conhecimento sobre os objetos resultasse das relações de suas ações, e que diverge de uma interpretação aristotélica, por exemplo. Da concepção mecânica de Aristóteles: "uma pedra cai porque há nela um propósito intrínseco em dirigir-se, como se verá, para o centro do universo que é o seu lugar natural" (PEDUZZI, 1996, p. 50). Esta concepção aristotélica de mundo direciona o estudo dos fenômenos para os objetos particulares, neste caso, a pedra. Contudo, esse direcionamento do olhar dificultaria ou até mesmo impediria nossa compreensão clássica de gravidade não como propriedade intrínseca de um objeto, mas como fruto de uma relação entre corpos. O domínio das relações teóricas permite que os estudantes possam trabalhar com uma infinidade de casos concretos.

Assim, afinamos o que queremos dizer por ter o conhecimento teórico de um fenômeno: referimo-nos aos processos pelos quais um objeto passa a ser ou deixa de $\operatorname{ser}^{4}$, isto

\footnotetext{
${ }^{4}$ Em inglês temos a expressão "being and nonbeing" (DAVYDOV, 1990, p. 126) de Lenin com referência à Hegel. Também, ao longo da obra de Davydov (1990), é utilizado o termo "appearance", que entendemos como tendo duplo significado, ambos apropriados: é tanto no sentido da maneira que o objeto aparece para nós, quanto
} 
é, suas relações, por serem teóricas, estão presentes em todos os casos concretos. Tais relações são necessárias para entender o comportamento ou a natureza de determinado objeto, explicando o processo de gênese e seu desenvolvimento.

Em síntese, na teoria do ensino desenvolvimental de Davydov busca-se desenvolver o pensamento de maneira a refletir as relações essenciais presentes nos fenômenos. As relações teóricas estão relacionadas com a universalidade, isto é, com a sua presença em todos os casos concretos. Assim, procurar pelas relações teóricas do eletromagnetismo significa procurar pelas relações que explicam a gênese e o desenvolvimento dos fenômenos eletromagnéticos. A ascensão para o concreto e do concreto para o abstrato é entendida como pensamento teórico.

Com a apresentação do referencial teórico, podemos enriquecer o problema de investigação: (i) entendemos que o ensino escolar deve almejar o desenvolvimento do pensamento teórico nos escolares; (ii) para isso, devemos trabalhar com as relações teóricas do conteúdo. Logo, retomamos o problema agora solidificado no referencial davydoviano: e quais podem ser essas relações teóricas no contexto do ensino de eletromagnetismo? Qual pode ser um modelo teórico dessas relações?

\section{Modelos na perspectiva do ensino desenvolvimental}

Estamos interessados em expressar a eletromagneticidade em forma de um modelo teórico, pois neste formato operações com um objeto permitem expressar propriedades que não são reveladas operando empiricamente. Davydov (1990) reconhece o potencial da utilização de modelos para o ensino ao concebê-lo como uma ferramenta simbólica que permite a organização do conhecimento sobre um determinado objeto. Pautando-se em Shtoff, Davydov (1900) ressalta que as condições de criações do modelo devem permitir que as relações teóricas formem uma determinada estrutura que permita tanto a redução ao concreto quanto a ascensão ao abstrato. Baseando-nos em Gaspar (1997) podemos questionar: como alguém que não conhece o modelo do átomo e a movimentação de cargas elétricas, poderia dizer o que acontece com papeizinhos atraídos com um bastão, após este ser atritado com um lenço?

O modelo é compreendido tanto como o ponto de partida quanto o ponto de chegada da atividade de investigação. Como universal, as relações teóricas formam "o modelo original (protótipo) e a escala para avaliar as coisas com as quais o indivíduo se encontra empiricamente" (DAVYDOV, 1988a, p. 130), sendo assim um modo de pensamento central na teoria do ensino desenvolvimental, na tradição do conhecimento teórico (HEDEGAARD, 2002; HEDEGAARD; CHAIKLIN, 2005). Cunha (2014, p. 98) apresenta uma síntese da função dos modelos teóricos na perspectiva desenvolvimental:

no sentido da maneira que o objeto passa a ser. Ou seja, o termo simboliza tanto o objeto aparecer para os nossos sentidos quanto surgir em essência. 
Esses modelos servem como um elo entre o conceito abstrato (geral, universal) e a concretização objetal, isto é, o objeto concreto presente na realidade social sob uma diversidade de formas de se manifestar. Importante destacar que, sob essa perspectiva teórica, trabalhar com modelos não significa moldar um pensamento e forma de ação com o objeto, mas possibilitar ao indivíduo o processo cognitivo de criação do modelo semiótico que representa o objeto real e concreto, inclusive em suas transições e transformações, em seu movimento real, e não de forma fixa e estática.

Portanto, nosso entendimento é que um modelo teórico consiste na identificação e possibilidades de usos das relações teóricas. Trabalhos em ensino de física que se baseiam em Davydov determinaram como núcleos conceituais: "a ideia de movimento" no conteúdo de mecânica (MARENGÃO, 2011, p. 45) e "resistência à variação do estado de movimento; relação entre força resultante, massa e aceleração; forças opostas" no conteúdo de leis de Newton (BORGES, 2016, p. 107). Contudo, a majoritária produção acadêmica em relação à Davydov está relacionada aos conteúdos da matemática, como apresentado em Khidir (2006), Rodrigues (2006), Cunha (2014), Rosa e Damazio (2017), entre outros.

Davydov (1990, p. 80-81) aponta pelo menos três diferentes camadas de trabalho em relação à elaboração de um modelo teórico para o ensino. A primeira consistindo em um trabalho lógico-epistemológico da descrição do conteúdo, dos seus princípios e relações teóricas. A segunda consiste no estudo dos mecanismos psicológicos que permitam a formação do pensamento teórico nos escolares, uma descrição das atividades intelectuais da criança que lhe permita se apropriar do pensamento teórico. O terceiro é a criação e uso de estratégias didático-metodológicas que criem possibilidades para os estudantes trabalharem com as relações teóricas. Nesse trabalho discutimos a primeira camada, a delineação das relações teóricas do ensino de eletromagnetismo a partir de princípios dialéticos da construção do conhecimento.

\section{Uma proposta de modelo teórico para eletromagneticidade}

Ao considerarmos que os conceitos científicos são fruto de uma construção lógica, histórica e cultural, a análise para compreensão da essência dos conceitos nos moldes da teoria do ensino desenvolvimental requer um estudo lógico histórico da gênese e do desenvolvimento dos conceitos (BORGES, 2016). Do ponto de vista da organização do conteúdo, nota-se, ao analisar diferentes manuais didáticos como a coletânea de Machado (2000, 2002, 2006) ou livros como Purcell (1970), Hewitt (2002), Young e Freedman (2009) uma abundância de conceitos de origem científica, leis, definições e aplicações da teoria eletromagnética. 
Nesse momento, podemos nos questionar se todos os conceitos de origem científica apresentados como, por exemplo, eletrosfera, efeito pelicular, capacitância, força eletromotriz etc são teóricos - em sentido davydoviano - em relação ao eletromagnetismo. Noutras palavras, os manuais didáticos não nos ajudam a direcionar a investigação para quais podem ser as relações teóricas, uma vez que estes apresentam, discutem e trabalham o máximo possível. Desse modo, analisamos artigos e trabalhos de pós-graduação que se propuseram a elaborar um modelo conceitual para o eletromagnetismo, independente do referencial teórico adotado pelos autores. Encontramos diversos exemplos de mapas conceituais para o eletromagnetismo (CUDMANI; FONTDEVILA, 1989; BAGNO; EYLON, 1997; MOREIRA, 2006; LABAS, 2016;) para eletrostática (SALÉM, 1986), sobre as equações de Maxwell e das ondas eletromagnéticas (GRIGORE; MIRON; BARNA, 2013).

Com esse movimento, percebemos que alguns conceitos de origem científica aparecem com mais frequência ou com mais relevância. Estes são aqueles que se referem à carga elétrica, campo eletromagnético, força elétrica, potencial elétrico, corrente elétrica, indução eletromagnética e ondas eletromagnéticas. Como discutido anteriormente, a teoria do ensino desenvolvimental demanda que delimitemos as relações teóricas uma vez que queremos formar um modelo. Portanto, devemos nos questionar se há relações que sustentariam todos esses conceitos, de que forma elas poderiam ser, e como elas se concretizam. Em trabalho anterior, Fontes (2020, p. 60-78) apresenta e discute a gênese e o processo de desenvolvimento destes conceitos selecionados para análise. Ao final, sugere que ao longo do desenvolvimento histórico do eletromagnetismo, da China antiga ao início do século XX, as diferentes explicações que se debruçaram sob o estudo do eletromagnetismo podem ser sustentadas pelas relações de movimento, variação e interação.

Para exemplificar a análise, destacamos de Fontes (2020) apenas alguns elementos que levaram à construção das propriedades do que atualmente chamamos de corrente elétrica. Na antiga Grécia, por volta de 570 a.C., há registros que o âmbar esfregado exercia influência em determinados objetos (PESSOA JUNIOR, 2010). Na época, alguns materiais atritados transferiam determinadas virtudes (TONIDANDEL; ARAÚJO; BOAVENTURA, 2018). A ideia de transferência de virtude cairia em desuso e Jerome Cardan no século XVI registraria que o âmbar possui qualidade de atração, agindo sobre a matéria (ROLLER; ROLLER, 1957). A noção que a eletricidade era propriedade do corpo ainda continuaria com William Gilbert que classificou os materiais em elétricos e não elétricos caso eles atraíssem ou não atraíssem corpos leves (CHAIB; ASSIS, 2007; PESSOA JUNIOR, 2010; TONIDANDEL; ARAÚJO; BOAVENTURA, 2018). Pessoa Junior (2010) pontua que a eletricidade seria material, agindo através de eflúvios invisíveis. Desse modo a atração deixaria de ser uma propriedade do corpo, mas preencheria o espaço ao seu redor com alguma espécie de fluido (SIQUEIRA; PIETROCOLA, 2004).

A ideia de fluido elétrico ganhou diferentes interpretações: Benjamin Franklin sugeria um fluido elétrico único, enquanto Charles Du Fay compreendia dois tipos de 
eletrização (BELÉNDEZ, 2008). Com a invenção da garrafa de Leiden, a eletricidade conseguia ser armazenada (JARDIM; GUERRA, 2017a) para depois ser liberada, apresentando um movimento materializado em brilhantes faíscas. Com a pilha de Volta, o movimento da eletricidade era observado pelo contato de pares metálicos em série. As diferentes formas de observação do movimento da eletricidade - produzidas pela eletrização por atrito ou por fenômenos galvânicos - era fonte de desacordo em relação à natureza da eletricidade (MARTINS, 1999), sendo o consenso apenas a existência do movimento.

A compreensão da eletricidade como fluido elétrico único deu lugar à existência de dois fluidos elétricos diferentes, defendidos por Coulomb e também por Oersted (DARRIGOL, 2000; GARDELLI, 2008). Com Oersted, eletricidade e magnetismo passaram a ser vistas como fenômenos relacionados, embora distintos. Wilhelm Weber sugeria a redução de todos os fenômenos elétricos ao movimento mecânico de fluidos elétricos. A noção de fluido elétrico não convenceria Faraday, que sistematicamente evitou essa interpretação e visualizava fenômenos eletromagnéticos com auxílio de linhas de força, que se complexificaram com o tempo e eventualmente culminaram no termo tubos de força. O termo tube foi utilizado por Maxwell para se referir à lei de indução eletromagnética de Faraday. Assim, em vez de utilizar o termo de Faraday lines of force; Maxwell, Poynting e outros também utilizaram tubes of force (DARRIGOL, 2000). Uma rejeição contundente dos fluidos elétricos seria vista na teoria eletrodinâmica de Heinrich Hertz, visto que para ele seria o ether field a fundação teórica da qual os outros conceitos seriam derivados (DARRIGOL, 2000, p. 258). Desenvolvimentos prosseguiram com Wiechert, J.J. Thomson, Lorentz até formarmos o conceito de corpúsculo, precursor da noção atual de elétron no eletromagnetismo clássico.

$\mathrm{O}$ que queremos destacar do trecho apresentado é: mesmo que o agente tenha sido identificado e interpretado através de diversos nomes e significados (virtude, único fluído, fluídos, linhas de força, éter, partículas), eles parecem ser construídos sob alguma concepção ligada ao movimento, seja ela transferência, passagem, transporte, entre outras interpretações. Neste sentido, por exemplo, descreve-se o movimento de uma agulha imantada quando há a passagem de uma corrente elétrica. A noção de corrente elétrica já foi interpretada como um único fluido, ou fluídos invisíveis, ou interação entre íons, ou partículas invisíveis até chegar ao conceito moderno de fluxo de elétrons. Embora os agentes mudassem por conta da linguagem utilizada entre diferentes pesquisadores (DARRIGOL, 2000; BEZERRA, 2006), o apelo à ideia de movimento de algo ou passagem de algo estava presente nos diferentes discursos, de diferentes personagens ao longo da construção histórica do conceito de corrente elétrica. Fontes (2020) realiza semelhante análise para justificar que o mesmo pode ser dito em relação à noção de variação e interação.

Portanto, propomos um primeiro modelo para o ensino de eletromagnetismo a partir das relações teóricas de movimento, variação e interação que sustentam as leis e conceitos que temos. Destinamos comentários às equações de Maxwell no item VIII deste artigo, ao sugerir que movimento e variação sejam explicitados separadamente no modelo por 
simplicidade. Ademais, Fontes (2020, p. 76-78) sugere que os resultados previstos pela lei de Gauss podem ser postulados à parte ao modelo, visto que "a lei de Gauss não constitui mais uma lei física das interações eletrostáticas, mas é equivalente à lei de Coulomb" (SALÉM, 1986, p. 86).

A partir do ensino desenvolvimental, o modelo se direciona a uma organização específica de pensamento e conhecimento de um objeto, evento ou fenômeno. Assim, ele se destina ao entendimento e explicação de eventos e situações concretas de vida dos estudantes (DAVYDOV, 1988b; HEDEGAARD; CHAIKLIN, 2005). Um modelo também precisa exprimir como essas relações se concretizam em casos particulares. Para isso, trabalhamos um exemplo da geração, transmissão e uso da energia elétrica.

\section{Pensando o uso do modelo: como tenho energia elétrica em casa?}

Nesse momento propomos uma atividade reflexiva que poderia guiar um planejamento de atividades no ensino de eletromagnetismo. Ressaltamos que a discussão a seguir não foi aplicada em sala de aula.

Muitas etapas precisam acontecer para que um morador de uma grande cidade consiga esquentar sua comida no forno de microondas. As principais etapas nesse amplo contexto da energia elétrica são geralmente divididas em geração, transmissão e distribuição (CAMPOS, 2017). Segundo a Agência Nacional de Energia Elétrica, o Estado de São Paulo apresenta 48 diferentes Usinas Hidrelétricas. Sendo as hidrelétricas responsáveis por mais da metade da produção de energia elétrica em São Paulo, optamos por utilizá-las como exemplo. Embora os detalhes da produção de energia elétrica variem dependendo do tipo de usina, todas têm por finalidade a produção de energia elétrica através do aproveitamento do potencial hidráulico existente em rios ou barragens.

Usaremos ao longo de toda nossa discussão a Fig. 1 elaborada por Lago, Ortega e Mattos (2020) para exemplificar o contínuo movimento entre o abstrato e o concreto a partir das relações teóricas.

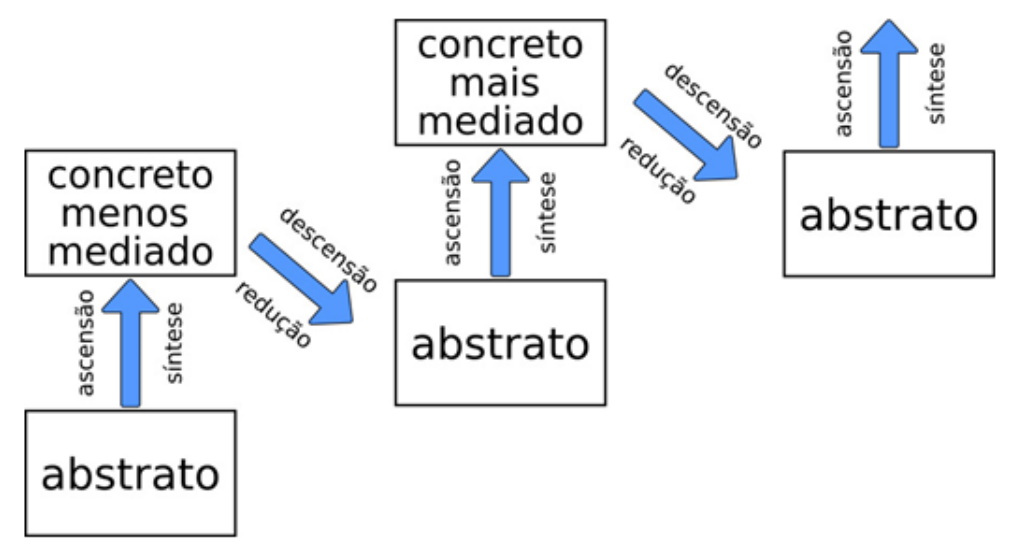

Fig. 1 - Múltiplos movimentos de descensões e ascensões no processo de formação e compressão dos conceitos. Fonte: Lago, Ortega e Mattos (2020, p. 127). 
Ao levantar o questionamento "como posso esquentar minha comida em casa com o microondas?", poderíamos começar relacionando uma noção de movimento "algo acontece para a energia elétrica chegar aqui em casa". Com o suporte do professor, trabalhamos a abstração do conceito de movimento de uma maneira ampla, com diferentes exemplos no eletromagnetismo, para então aplicá-lo ao problema investigado "o que se movimenta no nosso caso?". Ora, primeiro o movimento se concretiza na noção da conversão da energia mecânica do fluxo de água em energia elétrica nas turbinas que estão acopladas a um gerador elétrico.

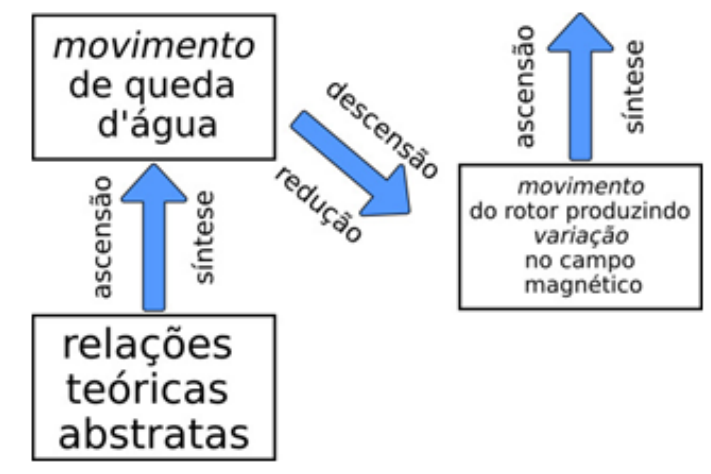

Fig. 2 - Parte dos movimentos de descensões e ascensões no processo de compreensão do aquecimento da comida com o microondas.

Contudo, vimos que não é qualquer movimento que nos interessa, mas sim aquele capaz de produzir uma variação. Variação do quê? Do campo magnético ou da corrente elétrica em um condutor. Nesse momento, novamente com a ajuda do professor, ascendemos a um abstrato mais generalizado: "o que significa variar um campo magnético ou uma corrente elétrica? Variar no espaço? No tempo? A intensidade? O ângulo?”.

No contexto da geração de energia por uma hidrelétrica, em particular para a transmissão, é economicamente mais vantajoso a produção de corrente alternada. $\mathrm{Na}$ produção de corrente alternada há variação do fluxo magnético que passa através de uma bobina, que por sua vez está conectada a um circuito que possui ao seu final um transformador. Em geral, a produção de energia elétrica acontece afastada dos grandes centros urbanos. Com isso, a eletricidade gerada nas hidrelétricas percorre longas distâncias em um complexo sistema de transmissão, devido ao uso dos transformadores. Simplificaremos o processo de transmissão tendo como foco o fenômeno físico relacionado à propagação de energia eletromagnética nos cabos condutores.

A transmissão de energia só é possível pois existe uma interação entre o campo elétrico e o campo magnético. Alguma interação entre os campos precisava existir uma vez que não é possível termos uma onda puramente elétrica que se propaga através do espaço, isto é, uma onda composta apenas de um campo elétrico. Essa impossibilidade se deve ao fato que 
uma onda puramente elétrica teria um campo elétrico variante. Esse campo elétrico variante necessariamente gera um campo magnético, portanto uma onda puramente elétrica é impossível (YOUNG; FREEDMAN, 2009). O inverso também é verdadeiro: não há onda puramente magnética.

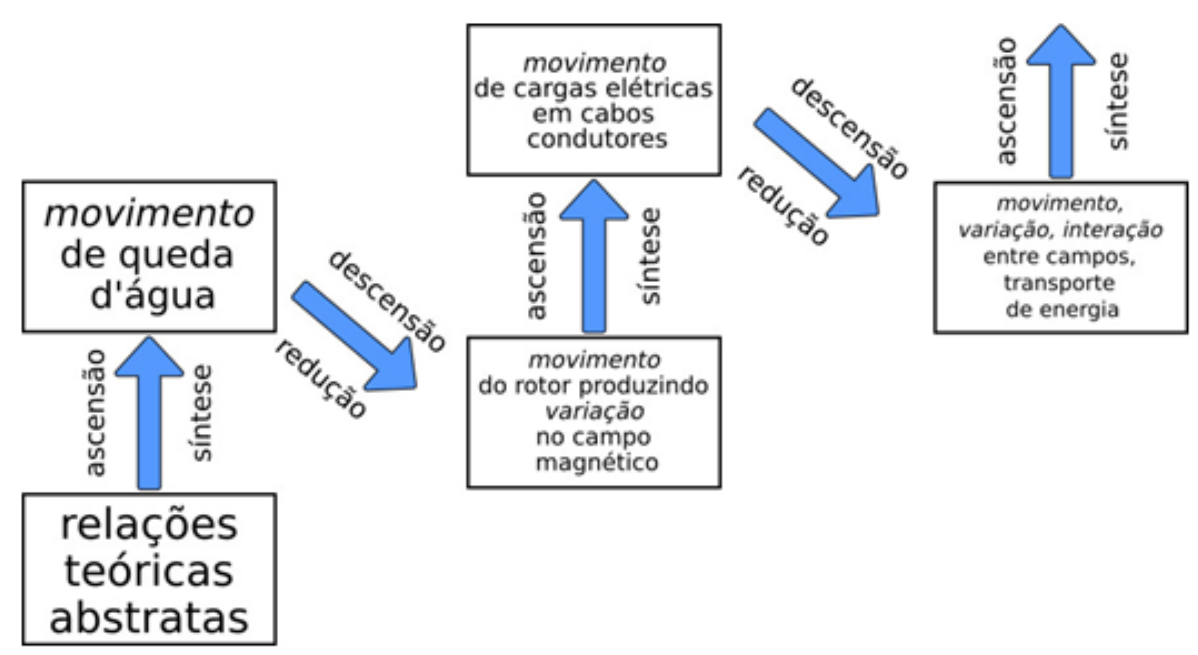

Fig. 3 - Continuação da Fig. 3, considerando mais algumas etapas do processo.

Ao final desse processo temos acesso à energia elétrica. Com isso, somos capazes de obter iluminação elétrica e ligar na tomada os mais variados tipos de aparelhos elétricos. $\mathrm{O}$ aparelho eletrodoméstico que nos interessa é o forno de microondas.

Esse forno elétrico é capaz de produzir ondas eletromagnéticas na faixa de frequência entre $300 \mathrm{MHz}$ e $300.000 \mathrm{MHz}$, e é composto principalmente por três componentes: magnetron, guia de ondas e a cavidade (SOUZA; NOGUEIRA; RASSINI, 2002). Tanto o guia de ondas quanto a cavidade são compostos por paredes refletoras e são construídos com a função de direcionar as microondas produzidas no magnetron para a cavidade e evitar perdas de energia.

$\mathrm{O}$ aquecimento de uma amostra no microondas acontece pois há uma interação entre as moléculas da amostra com a radiação eletromagnética. A absorção da radiação das microondas por íons dissolvidos e pelos solventes se deve principalmente a dois mecanismos: rotação de dipolos e migração iônica (SOUZA; NOGUEIRA; RASSINI, 2002).

$\mathrm{O}$ mecanismo da rotação de dipolos faz referência à característica de que a molécula da água é polar. Ou seja, a molécula da água apresenta polo positivo e polo negativo, formando um dipolo elétrico. Assim, ela é capaz de se alinhar com o campo elétrico externo das microondas, que varia com o tempo. Nesse processo, as moléculas polares que compõe o alimento tendem a se alinhar com o campo incidente. Essa constante tentativa de se alinhar com o campo elétrico incidente resulta no aumento da energia cinética das moléculas e, consequentemente, no aumento da temperatura do alimento. 


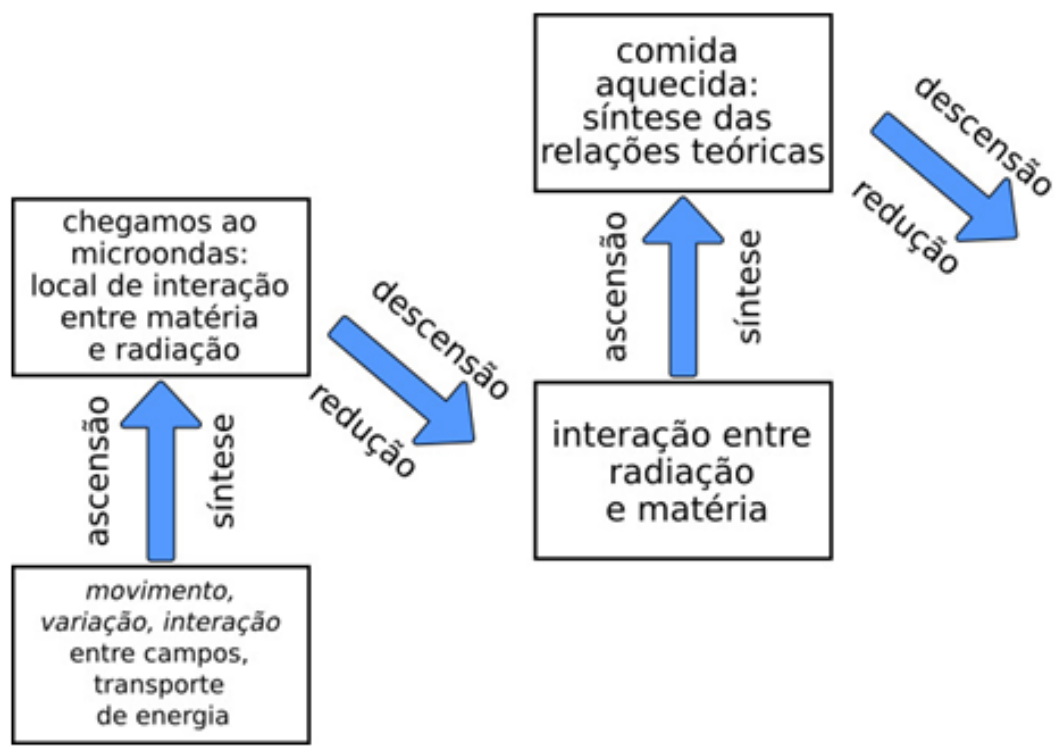

Fig. 4 - Continuação da Fig. 3, considerando mais algumas etapas do processo. Mantivemos a última seta de descensão/redução para ilustrar que o movimento de ascensão e redução é permanente.

Desse modo, vemos como esse processo pode apresentar novos concretos, sínteses das relações teóricas abstratas. A cada síntese os alunos devem ser estimulados a pensarem e produzirem de maneira criativa e autônoma "qual máquina produz determinada variação? Como eu [aluno] posso melhorar essa máquina ou imaginar uma diferente? Quais são alguns dos desafios da engenharia? Quais foram os processos históricos que culminaram na criação e no uso de tal máquina pela sociedade atual? Por que essa máquina não surgiu antes na história da humanidade? O que faltava e o que se alterou em nosso conhecimento? Qual a relação custo-benefício das máquinas que temos? Por que a minha comida não esquentou? Há outras máquinas que geram energia elétrica de forma menos danosa ao meio ambiente? Diferentes sociedades ou culturas utilizam os mesmos equipamentos? Como a máquina de determinado local ou sociedade funciona? Como as relações teóricas se concretizam nessas máquinas?”. Para compreender os processos que envolvem a criação e o uso do maquinário na vida cotidiana, precisamos dominar as relações teóricas apresentadas. É evidente que a profundidade de investigação e a autonomia dos alunos devem ser dosadas conforme o grau de instrução e o objetivo da atividade de ensino.

O modelo teórico permite, em hipótese, que trabalhemos com todos os diferentes exemplos concretos. Os estudantes podem propor outros questionamentos: "como funciona a conexão sem fio (bluetooth, wi-fi)?" E agora? Por onde começar a investigação? Ora, por que não começar investigando as relações teóricas, as maneiras de que elas se concretizam nesse caso particular? Será que para compreender conexões sem fio, precisamos do conceito de variação? Ou seria interação? Ou uma combinação de ambos? De que maneira eles se combinam? Há uma relação mais predominante? Qual? 
Uma vez escolhido(s) o(s) conceito(s) inicial(is) de análise - note que aqui estamos no campo abstrato - então questiona-se: como esse conceito se apresenta nesse novo caso da conexão sem fio? Algo interage? O que e como? Como eu posso investigar essa relação? Temos o suficiente para compreender o fenômeno? O que já sabemos sobre ele? E aqui voltamos ao concreto, um novo concreto, ampliado, complexificado (MATTOS, 2014; LAGO; ORTEGA; MATTOS, 2020). Esse movimento de vaivém é perpétuo e caracteriza o pensamento teórico que esperamos da educação escolar em geral, e do ensino de física em particular.

A partir desses movimentos entre as relações teóricas e as práticas sociais que envolvem o eletromagnetismo, constrói-se e promove-se o desenvolvimento intelectual dos alunos, permitindo que eles atuem autonomamente com relação aos objetos, ponto central da teoria do ensino desenvolvimental davydoviana.

\section{Algumas sínteses sobre a eletromagneticidade}

Enfatizamos que as relações teóricas que formam o modelo estão intimamente relacionadas e em diversos momentos se misturam, se somam e se concretizam de diferentes maneiras nas atividades de pesquisa e ensino. Mudanças em qualquer um dos conceitos refletem em mudanças por todo o modelo teórico (HEDEGAARD, 1996). Nessa seção abordamos algumas sínteses sobre a discussão das relações teóricas.

1) Sobre a separação entre movimento e variação. Peguemos como exemplo a lei de Faraday, que em uma espira fechada pode ser enunciada como "a força eletromotriz induzida em uma espira fechada é dada pela taxa de variação do fluxo magnético, com o sinal negativo, através da área delimitada pela espira" (YOUNG; FREEDMAN, 2009, p. 283). O eletromagnetismo clássico compreende corrente elétrica como um fluxo ordenado de elétrons. Como sabemos, fluxo ordenado de elétrons pode ser constante; isto é, uma determinada quantidade de carga que atravessa uma seção transversal de um condutor durante um intervalo de tempo pode ser um escalar. O que estamos sugerindo é que a noção de corrente elétrica já é construída a partir de uma noção de movimento; contudo, para termos o efeito da indução eletromagnética, precisamos que a corrente - que já se entende como um movimento - varie com o tempo. Noutras palavras, a corrente induzida em um circuito próximo depende da variação da corrente indutora. Nota-se que o mesmo resultado se daria com o movimento relativo não uniforme entre duas espiras. Portanto, para compreender a lei de Faraday faz-se o uso de dois conceitos distintos: movimento e variação.

Também pode-se olhar a lei de Ampère: $\nabla \times \vec{B}=\mu_{0} \vec{J}+\mu_{0} \epsilon_{0} \frac{\partial \vec{E}}{\partial t}$. Os termos $\mu_{0} \mathrm{e}$ $\epsilon_{0}$ são constantes relacionadas ao meio e não modificam a análise a seguir: o primeiro termo representa a corrente de condução, o segundo termo representa a variação da densidade de carga no tempo. Perceba que, nessa equação, se tem tanto uma noção de movimento (expressa 
por $\vec{J}$ ) quanto de variação $\left(\frac{\partial \vec{E}}{\partial t}\right)$. No caso de um deslocamento constante de cargas em determinada região do espaço, este último termo seria nulo. Desse modo, a lei de Ampère mostra que campos magnéticos são formados tanto por correntes elétricas (movimento) quanto pela variação da densidade de cargas.

Decerto que um modelo teórico pode ser apresentado com apenas movimento e interação, caso a noção de movimento seja ampliada a fim de abarcar a noção de variação apresentada. A questão que propomos é se ampliar a noção de movimento para englobar variação é realmente mais útil, uma vez que as leis de Ampère e de Faraday já distinguem esses dois conceitos.

2) Sobre o campo eletromagnético. O campo eletromagnético é uma expressão particular das relações teóricas do modelo. Mais precisamente, o campo eletromagnético é uma forma de concretização da relação teórica de interação.

Atualmente, o eletromagnetismo clássico usual adota noções de campo, e as equações de Maxwell - com consideráveis aperfeiçoamentos e contribuições de Helmholtz, Heaviside, Lorentz e outros - para interpretação e explicação dos seus fenômenos. Porém, mesmo nos dias atuais, definições de campo elétrico (ou magnético) são variadas e não é claro o consenso para além da matematização. Por exemplo, Rocha (2009, p. 1606) se refere a campo como "uma espécie de 'substância eletromagnética' com uma única estrutura", enquanto Hewitt (2002, p. 380) o entende como "uma espécie de aura que se estende através do espaço". Segundo Oliveira (2019, p. 15) o campo elétrico "pode ser imaginado como um 'campo de linhas invisíveis' no qual o centro é a própria carga que o gerou”.

Serway e Jewett (2004, p. 685) preferem adotar uma descrição mais pragmática: “um campo elétrico existe em um ponto se uma partícula de prova carregada colocada em repouso nesse ponto experimentar uma força elétrica". À luz dessa interpretação, Bezerra (2006) adiciona que a propriedade disposicional é necessária, porém insuficiente para caracterizar o campo eletromagnético, visto que essa propriedade também é presente em outros constructos matemáticos como o potencial.

Em uma análise do conceito de campo em diferentes livros didáticos, Silva e Krapas (2007) e Krapas e Silva (2008) apontam múltiplas atribuições dadas ao termo a depender do livro e do autor, a saber: campo é região; campo é vetor; campo é alteração do espaço; campo como curvatura do espaço; campo armazena energia; campo interage com partículas, medeia a interação entre elas; campo se propaga, é suporte para a propagação de energia; campo preenche o espaço. Purcell (1970, p. 17) bem resume a discussão sobre campo:

Talvez você ainda queira perguntar: que é um campo elétrico? É alguma coisa real, ou é meramente o nome de um fator numa equação o qual deve ser multiplicado por alguma outra coisa para dar o valor numérico da força que medimos numa experiência? Duas observações podem ser úteis aqui. Primeira: desde que funciona, não faz diferença. Esta não é uma resposta frívola, mas séria. Segunda: o fato de que o vetor campo elétrico num ponto do espaço é tudo o que precisamos conhecer 
para calcular a força em qualquer carga naquele ponto não é, de modo algum, trivial. Poderia ser de outra forma!

Desse modo, nossa proposição de modelo teórico não explicitamente apresenta campo eletromagnético, pois consideramos que mesmo com as suas mais variadas interpretações, ao serem aplicadas no contexto de práticas sociais ${ }^{5}$ que envolvem o eletromagnetismo, o conceito de campo é suficientemente compreendido com uma manipulação das relações teóricas propostas. Portanto, sugerimos: de um ponto de vista concreto, aquilo que se queira falar sobre campo, também pode ser falado por um arranjamento apropriado de movimento, variação e interação. De um ponto de vista abstrato, o que é campo, senão as suas relações?

3) A partir da teoria do ensino desenvolvimental, temos que as atividades de ensino de eletromagnetismo que almejam o desenvolvimento do pensamento teórico dos estudantes devem ser organizadas tendo as relações teóricas tanto como ponto de partida quanto ponto de chegada. Segundo Davydov (1990) o pensamento teórico é realizado em duas formas básicas: i) é feita uma generalização teórica, a partir da estrutura do conteúdo, na qual estabelece a essência do objeto em questão. Noutras palavras, a generalização teórica é expressa na forma das relações teóricas, da eletromagneticidade. Analisam-se dados reais relacionados ao conteúdo do eletromagnetismo juntamente a problemas que envolvem práticas sociais. A segunda forma básica ii) se dá na exposição das contradições das relações teóricas e uma determinação para sua aplicabilidade em casos concretos.

Note que a essência, relativa às ideias de movimento, variação e interação, se mantém, o que difere são as formas com que estas sintetizam o concreto, que mudam conforme os contextos sociais e culturais de cada escola, aluno e professor. Apesar de compreendermos o pensamento teórico em duas formas básicas, não existe meio pensamento teórico.

4) $\mathrm{O}$ modelo teórico oferece uma maneira de organizar as relações conceituais que inundam cada uma das áreas e, além disso, oferece uma sugestão de como conceitualizar as diferentes atividades de ensino (CHAIKLIN, 1999).

Desconhecemos uma organização semelhante na literatura, e a sua necessidade é latente: precisamos trabalhar com as relações essenciais para desenvolver o pensamento teórico; ótimo, mas quais podem ser essas relações se consideramos o ensino de eletromagnetismo? O próximo passo, que idealmente deveria ocorrer simultaneamente, é: como essas relações se concretizam em diferentes contextos e atividades de ensino? As formas de concretização necessariamente vão modificar o modelo teórico inicial, expandindoo e atribuindo-lhe significados. A Fig. 6 exibe que, embora haja diferentes processos aos

\footnotetext{
${ }^{5}$ Utilizamos prática social em sentido análogo a societal pratice ou social situation of development, ou ainda practical problems presente em Chaiklin (2002), Hedegaard e Chaiklin (2005), e Davydov (1998), respectivamente.
} 
quais a teoria do ensino desenvolvimental se refere, estes processos fazem parte de um todo conectado, dialeticamente influenciado.

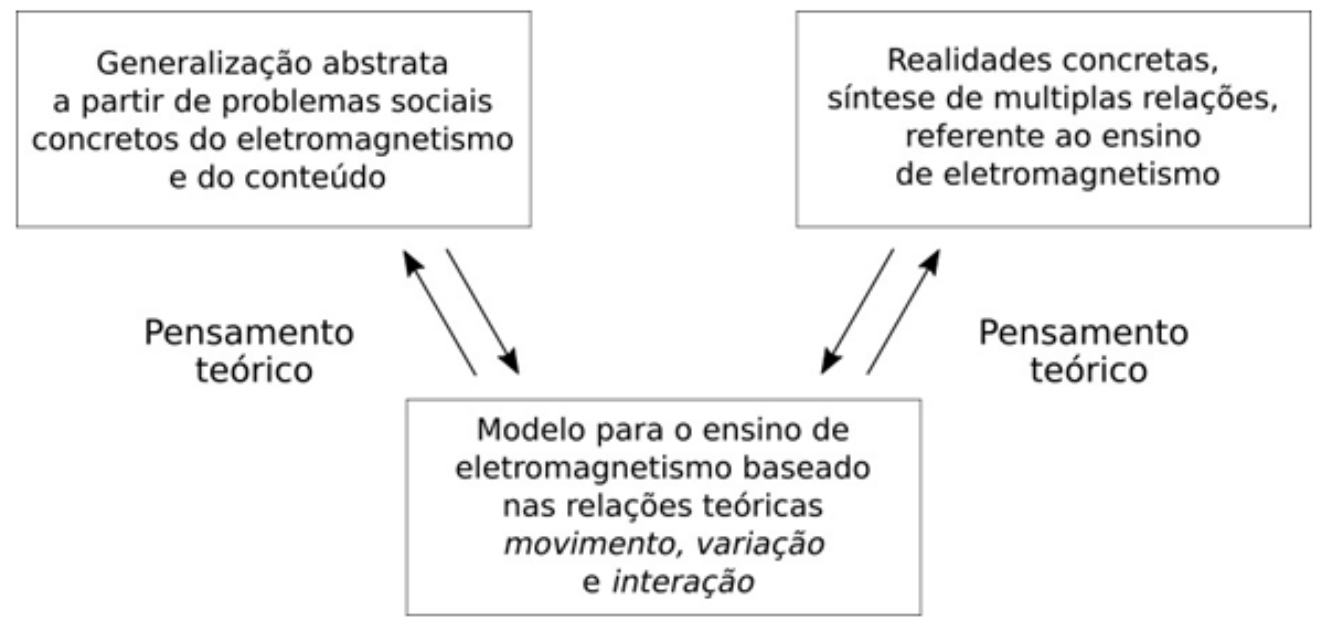

Fig. 5 - Dinâmica entre a generalização abstrata do conteúdo, do modelo teórico e sua concretização em diferentes contextos. Todo processo, representado pelas setas, é mediado pelo pensamento teórico e pelo modelo teórico na teoria do ensino desenvolvimental.

Chaiklin (1999, p. 191, tradução nossa) resume o processo ilustrado na Fig. 6 em termos como:

uma típica recomendação é começar com as relações básicas, investigar algumas variações dessas relações, tentar uma síntese via o modelo que captura os aspectos essenciais, aplicar o modelo para novos e casos relacionados e então avaliar a adequação do modelo teórico.

Chamamos atenção para esse trecho de Chaiklin (1999) "começar com as relações básicas". Delimitar e justificar quais poderiam ser tais relações é apenas o primeiro passo de um longo processo. Ao fim e ao cabo, a última palavra sobre a adequação do modelo teórico é do professor com seus alunos, pois ele é o único que conhece seus contextos e suas realidades materiais concretas. O que sugerimos é que o professor estruture as atividades de ensino estando consciente das relações teóricas, e permita que os estudantes descubram e investiguem as relações e as manifestações dessas leis gerais que formam a eletromagneticidade em diferentes exemplos concretos. Este é o caminho pelo qual a teoria do ensino desenvolvimental aponta uma chance maior do desenvolvimento da personalidade intelectual, em particular, do pensamento e conhecimento teórico. Isto pois a apropriação do conteúdo e o desenvolvimento intelectual se dão em um processo indissociável, simultâneo, transformando-se e expandindo-se mutuamente. 


\section{Considerações finais}

Este artigo se apresenta como uma reflexão teórica centrada na questão "o que" poderia compor o núcleo do ensino de eletromagnetismo. Há extensa pesquisa na literatura que sugere diferentes "comos", pautados nos mais diversos referenciais teóricos (FONTES; RODRIGUES, 2021). Realizamos uma possível síntese entre uma teoria própria do campo da psicologia com uma teoria do campo da física. A teoria do ensino desenvolvimental, pautada em pilares da teoria histórico-cultural, elaborada por Davydov (1988a, 1990) e colaboradores, aponta como função central da educação escolar a promoção do desenvolvimento do pensamento teórico nos estudantes. Para isso, Davydov (1988a, 1990) defende que há certas relações teóricas que são críticas e necessárias para o entendimento do atual estado de um objeto e de mudanças que ele possa vir a sofrer, e que é através da aquisição do conhecimento teórico que se estrutura a formação do pensamento teórico e, por conseguinte, o desenvolvimento psíquico da criança. Ao escolhermos como objeto de análise as relações teóricas do conteúdo de ensino do eletromagnetismo, identificamos as relações de movimento, variação e interação. Como explicado, estas não são abstrações formais e só ganham significados quando concretizadas. Assim, descrevemos uma proposta para pensar esses diversos movimentos entre o abstrato e o concreto a partir do modelo teórico, que também chamamos de eletromagneticidade.

Como resultado, sugerimos que não é porque o eletromagnetismo possui um corpo sólido de conhecimento que todos esses conceitos seriam essenciais para uma compreensão que almeje o pensamento teórico. Noutras palavras, não é porque os conceitos são de origem científica que eles são relações teóricas às quais o ensino desenvolvimental se refere, e é necessário investigação por parte das pesquisas em Ensino de Física.

Desse modo, pensamos que uma importante discussão que contribuiria significativamente para essa área de pesquisa é: de um lado A) sabe-se, devido a fundamentações teóricas diversas, que o conceito de mediação ou o conhecimento prévio dos alunos, entre outros fatores, são importantes para aprendizagem efetiva dos alunos. De outro lado B) temos a partir do livro didático, da literatura ou da formação acadêmica, a presença de vários conceitos de origem científica. Basta escolher um conceito em B) e depois criar condições em sala de aula que estimulem a interação entre os alunos? Apoiando-nos na teoria do ensino desenvolvimental sugerimos que não, pois o problema é mais complexo que isso.

Na educação básica, o ensino de eletromagnetismo distribui a atenção no estudo de diversos conceitos como campo eletromagnético, potencial elétrico, capacitores, lei de Kirchhoff, entre tantos outros. Mas, no fundo, trabalham-se determinados conceitos atribuindo um valor per si. Nesse trabalho advogamos que tais conceitos podem ser selecionados e construídos a partir de significativas manipulações das relações teóricas que constituem o modelo discutido. Nossa proposta não busca reduzir todo o conhecimento e possibilidades a respeito do ensino de eletromagnetismo ao modelo teórico. Porém, 
assumindo que há um tempo limitado na educação básica, então educadores precisam tomar algumas decisões sobre qual deveria ser o foco do ensino.

Há muito trabalho a ser feito e são necessárias diferentes pesquisas e múltiplos olhares quando o objeto é o desenvolvimento de um modelo teórico para o ensino de eletromagnetismo, ou demais áreas da física. O próximo passo que daria continuidade à discussão é compreender como essas três relações teóricas se concretizam no trabalho educacional em sala de aula. Em outras palavras, nosso estudo aponta para a investigação das relações conceituais que permitam expressar os conteúdos teóricos no ensino de eletromagnetismo. Podemos dizer que as relações teóricas não existem no plano abstrato, uma vez que elas se concretizam e se complementam num agregado orgânico, se revelando nos movimentos de ascensão ao concreto e redução ao abstrato. As formas de concretização modificarão o modelo proposto uma vez que ele ganhará novo significado ao ser concretizado.

\section{Agradecimento}

O presente trabalho foi realizado com apoio da Coordenação de Aperfeiçoamento de Pessoal de Nível Superior - Brasil (CAPES) - Código de Financiamento 001.

\section{Referências bibliográficas}

BAGNO, E.; EYLON, B. From problem solving to a knowledge structure: An example from the domain of electromagnetism. American Journal of Physics, v. 65, n. 726, p. 726-736, 1997. Disponível em: <<https://aapt.scitation.org/>. Acesso em: 24 ago. 2020.

BELÉNDEZ, A. La unificación de luz, eletricidad y magnetism: la "sistensis electromagnética" de Maxwell. Revista Brasileira de Ensino de Física, v. 30, n. 2, 2601, 2008. Disponível em: <<https://www.scielo.br/rbef>. Acesso em: 24 ago. 2020.

BEZERRA, V. A. Maxwell, a teoria do campo e a desmecanização da física. Scientiae Studia, v. 4, n. 2, p.177-220, 2006. Disponível em: <https://www.scielo.br/>. Acesso em: 24 ago. 2020.

BORGES, L. B. Ensino e aprendizagem de física: contribuições da teoria de Davydov. 154f. Tese (Doutorado em Educação) - Pontifícia Universidade Católica de Goiás, Goiânia.

CAMPOS, L.B. Proposta de abordagem temática com enfoque CTS no ensino de física: produção de energia elétrica. 2017. 131 f. Dissertação (Mestrado em Educação em Ciências e Matemática) - Universidade Federal Rural do Rio de Janeiro. 
CASPERSON, J. M.; LINN, M. C. Using visualizations to teach electrostatics. American Journal of Physics, v. 74, n. 4, p. 316-323, 2006. Disponível em: $<$ https://aapt.scitation.org/>. Acesso em: 24 ago. 2020.

CHAIB, J.P.M C.; ASSIS, A. K.T. Distorção da obra eletromagnética de Ampère nos livros didáticos. Revista Brasileira de Ensino de Física, v. 29, n. 1, p. 65-70, 2007. Disponível em: $<$ https://www.scielo.br/rbef>. Acesso em: 15 maio 2020.

CHAIKLIN, S. Developmental teaching in upper-secondary school. In: HEDEGAARD, M.; LOMPSCHER, J. (Org.). Learning activity and development. Aarhus (Dinamarca): Aarhus Universitiy Press, 1999. p. 187-210.

CHAIKLIN, S. A developmental teaching approach to schooling. In: WELLS, G.; CLAXTON, G. (Org.). Learning for life in the 21 st century: sociocultural perspectives on the future of education. Blackwell publishing, 2002. p. 167-180.

COLIN, P.; VIENNOT, L. Using two models in optics: Students' difficulties and suggestions for teaching. American Journal of Physics, v. 69, n. S1, p. 36-44, 2001. Disponível em: $<$ https://aapt.scitation.org/>. Acesso em: 24 ago. 2020.

CUDMANI, L. C.; FONTDEVILA, P. Física básica: a organização de conteúdos no ensino aprendizagem do eletromagnetismo. Caderno Catarinense de Ensino de Física, v. 6, n. 3, p. 196-210, 1989.

CUNHA, A. L. A. Ensino de estatística: uma proposta fundamentada na teoria do ensino desenvolvimental. 2014. 128 f. Dissertação (Mestrado em Educação) - Pontifícia Universidade Católica de Goiás, Goiânia.

DARRIGOL, O. Electrodynamics from Ampère to Einstein. Oxford University Press: 2000.

DAVÝDOV, V. V. Tipos de generalización em la enseñanza. Havana: Pueblo y Educación, 1982.

DAVYDOV, V. V. Problemas do ensino desenvolvimental: a experiência da pesquisa teórica e experimental na psicologia. Tradução: José Carlos Libâneo; Raquel A. M. da Madeira Freitas. Soviet Education, Agosto, v. XXX, n. 8, 1988a. 
DAVYDOV, V. V. Learning Activity in the Younger School-age Period. Soviet Education, v. 30, n. 9, p. 3-47, 1988 b.

DAVYDOV, V. V. Types of Generalization in Instruction: Logical and Psychological Problems in the Structuring of School Curricula. National Council of Teachers of Mathematics. 1990.

DAVYDOV, V. V. The concept of developmental teaching. Journal of Russian and East European Psychology, v. 36, n. 4, p. 11-36, 1998.

DIAS, M. S.; SOUZA, N. M. M. A atividade de formação do professor na licenciatura e na docência. In: MOURA, M. O. (Org.). Educação escolar e pesquisa na teoria históricocultural. São Paulo: Loyola, 2017. p. 183-209.

FÁVERO, M. H.; SOUSA, C. M. S. G. A resolução de problemas em física: revisão de pesquisa, análise e proposta metodológica. Investigações em Ensino de Ciências, v. 6, n. 2, p.143-196, 2001. Disponível em: <https://www.if.ufrgs.br/cref/ojs/index.php/ienci/>. Acesso em: 20 fev. 2020.

FONTES, D. T. M. Uma análise do ensino de eletromagnetismo a partir da teoria do ensino desenvolvimental de Davydov. 2020. 122 f. Dissertação (Mestrado em Educação em Ciências) - Universidade de São Paulo, São Paulo.

FONTES, D. T. M.; RODRIGUES, A. M. Uma explicação para a escassez de trabalhos que utilizam a teoria do ensino desenvolvimental como referencial teórico no ensino de física no contexto nacional. In: SIMPÓSIO SUL-AMERICANO DE PESQUISA EM ENSINO DE CIÊNCIAS, I, 2020, Cerro Largo, Rio Grande do Sul. Atas... p. 1-5.

FONTES, D. T. M.; RODRIGUES, A. M. Fundamentação teórica no ensino de eletromagnetismo: uma revisão da literatura em periódicos nacionais. Caderno Brasileiro de Ensino de Física. Aceito para publicação, 2021.

GASPAR, A. Cinquenta anos de ensino de física: muitos equívocos, alguns acertos e a necessidade do resgate do papel do professor. In: XV Encontro de Físicos do Norte e Nordeste, XV, 1997, Natal, Rio Grande do Norte. Atas... p. 1-13.

GARDELLI, D. Antecedentes históricos ao surgimento do Eletromagnetismo. Caderno Brasileiro de Ensino de Física, v. 35, n. 1, p. 118-137, 2018. Disponível em: $<$ https://periodicos.ufsc.br/index.php/fisica/>. Acesso em: 24 ago. 2020. 
GRIGORE, I.; MIRON, C.; BARNA, E. S. Constructivist tools for the study of the special theory of relativity. In: INTERNATIONAL SCIENTIFIC CONFERENCE ELEARNING AND SOFTWARE FOR EDUCATION, $9^{\text {th }}, 2013$, Bucareste. Proceedings...

HEDEGAARD, M. How Instruction Influences Children's Concepts of Evolution, Mind, Culture, and Activity, v. 3, n. 1, p. 11-24, 1996.

HEDEGAARD, M. A zona de desenvolvimento proximal como base para o ensino. In: DANIELS, H. (Org.). Uma introdução a Vygotsky. São Paulo: Loyola, 2002. p. 199-227.

HEDEGAARD, M.; CHAIKLIN, S. Radical-local teaching and learning: a culturalhistorical approach. Aarhus N; Oakville, CT: Aarhus University Press, 2005.

HENDERSON, C.; DANCY, M.; NIEWIADOMSKA-BUGAJ, M. Use of research-based instructional strategies in introductory physics: where do faculty leave the innovation-decision process? Physical Review Special Topics - Physics Education Research, v. 8, n. 020104, 2012. Disponível em: <https://journals.aps.org/prper/>. Acesso em: 05 abril 2020.

HEWITT, P. G. Física conceitual. Porto Alegre: Artmed Editora, 2002.

ILYENKOV, E. V. Dialectical Logic, Essays on its History and Theory. Translated: H. Campbell Creighton. Progress Publishers, 1977.

ILYENKOV, E. V. Knowledge and Thinking. Journal of Russian \& East European Psychology, v. 45, n. 4, p. 75-80, ago. 2007.

JARDIM, W. T.; GUERRA, A. República das Letras, Academias e Sociedades Científicas no século XVIII: a garrafa de Leiden e a ciência no ensino. Caderno Brasileiro de Ensino de Física, v. 34, n. 3, p. 774-797, 2017a. Disponível em:

$<$ https://periodicos.ufsc.br/index.php/fisica/>. Acesso em: 24 ago. 2020.

JARDIM, W. T.; GUERRA, A. Experimentos históricos e o ensino de física: agregando reflexões a partir da revisão bibliográfica da área e da história cultural da ciência. Investigações em Ensino de Ciências, v. 22, n. 3, p. 244-263, 2017b. Disponível em: $<$ https://www.if.ufrgs.br/cref/ojs/index.php/ienci/>. Acesso em: 20 fev. 2020.

KHIDIR, K. S. Aprendizagem da Álgebra - uma análise baseada na teoria do ensino desenvolvimental de Davídov. 2006. 104 f. Dissertação (Mestrado em Educação) Universidade Católica de Goiás, Goiânia. 
KRAPAS, S.; SILVA, M. C. O conceito de campo: polissemia nos manuais, significados na física. Ciência \& Educação, v. 14, n. 1, p. 15-33, 2008. Disponível em: $<$ https://www.redalyc.org/pdf/2510/251019506002.pdf>. Acesso em: 24 ago. 2020.

LABAS, M. Uma proposta de abordagem histórico-experimental da lei de indução eletromagnética de Faraday à luz da teoria da aprendizagem significativa. 2016. $194 \mathrm{f}$. Dissertação (Mestrado em Ensino de Física) - Universidade Estadual de Ponta Grossa, Ponta Grossa.

LAGO, L.; ORTEGA, J. L.; MATTOS, C. O modelo genético e o movimento dinâmico entre abstrato e concreto como instrumentos para o planejamento de sequências didáticas para o ensino de ciências. Alexandria, v. 13, n.1, p. 123-153, 2020. Disponível em: $<$ https://periodicos.ufsc.br/index.php/alexandria>. Acesso em: 24 ago. 2020.

LIBÂNEO, J. C.; FREITAS, R.A.M.M. Vygotsky, Leontiev, Davydov-três aportes teóricos para a teoria histórico-cultural e suas contribuições para a didática. In: CONGRESSO BRASILEIRO DE HISTÓRIA DA EDUCAÇÃO, SBHE, IV, 2006.

LIBANEO, J.C.; FREITAS, R. A. M. M. Vasily Vasilyevich Davydov: a escola e a formação do pensamento teórico-científico. In: LONGAREZI, A. M.; PUENTES, R. V. (Org.). Ensino desenvolvimental: vida, pensamento e obra dos principais representantes russos. 3. ed. Uberlândia: EDUFU, 2017. p. 331-366.

MACHADO, K. D. Teoria do eletromagnetismo. Ponta Grossa: Editora UEPG. 2000. v. 1.

MACHADO, K. D. Teoria do eletromagnetismo. Ponta Grossa: Editora UEPG. 2002. v. 2.

MACHADO, K. D. Teoria do eletromagnetismo. Ponta Grossa: Editora UEPG. 2006. v. 3.

MARENGÃO, L. A. O ensino de física no ensino médio: descrevendo um experimento didático na perspectiva histórico-cultural. 2011. 144f. Dissertação (Mestrado em Educação) - Pontifícia Universidade Católica de Goiás, Goiânia.

MARTINS, R. A. Alessandro Volta e a invenção da pilha: dificuldades no estabelecimento da identidade entre o galvanismo e a eletricidade. Acta Scientiarum, v. 21, n. 4, p. 823-835, 1999. Disponível em: <http://periodicos.uem.br/ojs/>. Acesso em: 24 ago. 2020. 
MATTOS, C. R. Conceptual profile as a model of a complex world. In: MORTIMER, E.; ELHANI, C. N. (Org.). Conceptual profile: a theory of teaching and learning scientific concepts. 1. ed. Dordrecht: Springer, 2014. p. 263-291.

MOREIRA, M. A. Mapas conceituais e diagramas V. Porto Alegre: Ed. do Autor, 2006.

MÜLLER, M. G. et al. Uma revisão da literatura acerca da implementação da metodologia interativa de ensino Peer Instruction (1991 a 2015). Revista Brasileira de Ensino de Física, v. 39, n. 3, 2017. Disponível em: <https://www.scielo.br/rbef $>$. Acesso em: 15 mai. 2020.

OLIVEIRA, R. A. L. C. Aprendizagem baseada em problemas e o ensino do conceito de geração de energia elétrica. 2019. 74 f. Dissertação (Mestrado Profissional Ensino de Física) - Universidade Estadual Paulista.

OLIVEIRA, V.; ARAUJO, I. S.; VEIT, E. A. Resolução de problemas abertos no ensino de física: uma revisão da literatura. Revista Brasileira de Ensino de Física, v. 39, n. 3, 2017. Disponível em: <https://www.scielo.br/rbef>. Acesso em: 15 mai. 2020.

PANOSSIAN, M. L.; MORETTI, V. D.; SOUZA, F. D. Relações entre movimento histórico e lógico de um conceito, desenvolvimento do pensamento teórico e conteúdo escolar. In: MOURA, M. O. (Org.). Educação escolar e pesquisa na teoria histórico-cultural. São Paulo: Loyola, 2017. p. 125-152.

PEDUZZI, L. O. Q. Física aristotélica: por que não considerá-la no ensino da mecânica. Caderno Catarinense de Ensino de Física, v. 13, n. 1, p. 48-63, 1996.

PESSOA JUNIOR, O. Modelo causal dos primórdios da ciência do magnetismo. Scientiae Studia, v. 8, n. 2, 2010. Disponível em: <https://www.scielo.br/>. Acesso em: 24 ago. 2020.

PRESTES, Z.; TUNES, E.; NASCIMENTO, R. Lev Semionovitch Vigotski: um estudo da vida e da obra do criador da psicologia histórico-cultural. In: LONGAREZI, A. M.; PUENTES, R. V. (Org.). Ensino desenvolvimental: vida, pensamento e obra dos principais representantes russos. 3. ed. Uberlândia: EDUFU, 2017. p. 59-79.

PURCELL, E. M. Eletricidade e magnetismo. Curso de Física de Berkeley. São Paulo: Edgard Blucher Ltda, 1970. 
RIBEIRO, J. L. P.; VERDEAUX, M. F. S. Atividades experimentais no ensino de óptica: uma revisão. Revista Brasileira de Ensino de Física, v. 34, n. 4, 2012. Disponível em: $<$ https://www.scielo.br/rbef>. Acesso em: 15 mai. 2020.

ROCHA, J. F. M. O conceito de "campo" em sala de aula: uma abordagem históricoconceitual. Revista Brasileira de Ensino de Física, v. 31, n. 1, p. 1604.1-1604.17, 2009. Disponível em: $<$ https://www.scielo.br/rbef>. Acesso em: 24 ago. 2020.

RODRIGUES, V. L. G. C. Aprendizagem do conceito de volume e o desenvolvimento intelectual: uma experiência no ensino fundamental. 2006. 167 f. Dissertação (Mestrado em Educação) - Universidade Estadual de Maringá, Paraná.

ROLLER, D.; ROLLER, D. H. D. The development of the concept of electric charge: electricity from the Greeks to Coulomb. In: CONANT, J. B.; NASH, L. K. (Org.). Harvard Case Histories in Experimental Science. Cambridge-Massachusetts: Harvard University Press, 1957.

ROSA, J. E.; DAMAZIO, A. O ensino de matemática no primeiro ano escolar: uma articulação entre a proposição gepapeana e davydoviana. In: MOURA, M. O. (Org.). Educação escolar e pesquisa na teoria histórico-cultural. São Paulo: Loyola, 2017. p. 153182.

ROSA, J. E.; MORAES, S. P. G.; CEDRO, W. L. As particularidades do pensamento empírico e do pensamento teórico na organização do ensino. In: MOURA, M. O. (Org.). A atividade pedagógica na teoria histórico-cultural. Campinas: Autores Associados, 2016. p. 155-176.

SAĞLAM, M.; MILLAR, R. Upper high school students' understanding of electromagnetism. International Journal of Science Education, v. 28, n. 5, p. 543-566, 2006. Disponível em: $<$ https://www.tandfonline.com/doi/full/10.1080/09500690500339613>. Acesso em: 8 fev. 2019.

SALÉM, S. Estruturas conceituais no ensino de física: uma aplicação à eletrostática. 1986. 245 f. Dissertação. (Mestrado Ensino de Ciências). Instituto de Física e Faculdade de Educação, Universidade de São Paulo.

SCARINCI, A. L. et al. Modelos Representacionais da Estrutura da Matéria e o Ensino de Eletricidade. In: SIMPÓSIO NACIONAL DE ENSINO DE FÍSICA, XVIII, 2009, Vitória, ES. Anais... 
SERWAY, R. A.; JEWETT, J. W. Princípios de física: eletromagnetismo. Thomson Learning edições, 2004. v. 3.

SILVA, A. C. Eletromagnetismo e o Anti-Herói Magneto: Uma possível abordagem no ensino médio. Revista de Ensino de Ciências e Matemática, v. 3, n. 2, p. 125-135, 2012. Disponível em: <http://revistapos.cruzeirodosul.edu.br/index.php/>. Acesso em: 24 ago. 2020.

SILVA, M. C.; KRAPAS, S. Controvérsia ação a distância/ação mediada: abordagens didáticas para o ensino das interações físicas. Revista Brasileira de Ensino de Física, v. 29, n. 3, p. 471-479, 2007. Disponível em: <https://www.scielo.br/rbef $>$. Acesso em: 24 ago. 2020 .

SIQUEIRA, M. R. D. P.; PIETROCOLA, M. Uma breve discussão sobre campo eletromagnético na formação do professor. In: ENCONTRO DE PESQUISA EM ENSINO DE FÍSICA, IX, 2004, Jaboticatubas, MG. Atas...

SOUZA, G. B.; NOGUEIRA, A.R. A.; RASSINI, J. B. Determinação de matéria seca e umidade em solos e plantas com forno de microondas doméstico. Embrapa Pecuária Sudeste-Circular Técnica (INFOTECA-E), 2002.

STOCKLMAYER, S. Teaching direct current theory using a field model. International Journal of Science Education, v. 32, n. 13, p. 1801-1828, 2010. Disponível em: $<$ https://www.tandfonline.com/doi/full/10.1080/09500690903575748>. Acesso em: 2 fev. 2020.

TONIDANDEL, D. A. V.; ARAÚJO, A. E. A.; BOAVENTURA, W. C. História da Eletricidade e do Magnetismo: da Antiguidade à Idade Média. Revista Brasileira de Ensino de Física, v. 40, n. 4, 2018. Disponível em: <https://www.scielo.br/rbef>. Acesso em: 24 ago. 2020 .

VIGOTSKI, L. S. Pensamiento y habla. Tradução: Alejandro Ariel González. Buenos Aires: Colihue, 2007.

YOUNG, H. D.; FREEDMAN, R. A. Física III: eletromagnetismo. Tradução: Sonia Midori Yamamoto. São Paulo: Addison Wesley, 2009.

(cc) BY-NC-ND Direito autoral e licença de uso: Este artigo está licenciado sob uma Licença Creative Commons. 